tổn thương đám mờ nhỏ trên phim X-quang theo tiêu chuẩn của ILO hướng tới chẩn đoán mắc bệnh bụi phổi silic. Tất cả các đám mờ nhỏ phát hiện trền phim $X$ - quang đều có kích thước loại $\mathrm{p} / \mathrm{p}$ và có mât độ nằm ở phân nhóm chính nhóm 1 , trong đó, đám mờ có mật độ thuộc phân nhóm phụ $1 / 1$ chiếm tỷ lệ cao nhất với $75 \%$, đám mờ có mật độ thuộc phẩn nhóm phụ $1 / 2$ chiếm tỷ lệ $25,0 \%$. Kết quả nghiên cứu tương đồng với kết quả nghiên cứu của nhiều tác giả [6].

Đa số NLĐ không có rối loạn chức năng thông khí phổi, NLĐ có hội chứng hạn chế chiếm tỷ lệ cao nhất 10,9\%; tỷ lệ NLĐ có hôi chứng tắc nghẽn chiếm $6,4 \%$. Kết quả này phù hợp với đặc điểm bệnh lý của bệnh bụi phổi silic là bệnh là xơ hóa phổi dẩn đến giảm dung tích sống gây ra hội chứng hạn chế.

\section{KẾT LUÂNN}

Tỷ lệ hiện mắc bệnh bụi phổi của NLĐ tiếp xúc trực tiếp với bụi silic trong một số ngành nghề tại Phú Yên nằm 2020 là 1,8\%. NLĐ mắc bệnh bụi phổi silic tập trung ở loại hình sản xuất đá granit (100\%). Tỷ lệ NLĐ có các triệu chứng ho, khạc đờm, đau ngực, khó thở, rì rào phế nang giảm lần lượt là $6,8 \%, 7,7 \%, 2,3 \%, 2,3 \%$, $0,5 \%$. Các rối loạn thông khí và tổn thương nhu mô phổi trên phim X - quang mà NLĐ gặp phải đa số là thể nhẹ.

\section{TÀI LIÊU THAM KHẢO}

1. ILO in Vietnam (2013). ILO calls for urgent global action to fight occupational diseases,

<http://www.ilo.org/hanoi/Informationresources/Publi cinformation/Pressreleases/WCMS_211709/lang-vi/index.htm>, xem ngày 10/05/2018.

2. Nguyễn Quảng Thức (2013). Thực trang bệnh nghề nghiêp trên thế giới và ở Việt Nam, $<$ http://moh.gov.vn/pcbenhnghenghiep/pages/tint uc.aspx? CateID $=9 \&$ ItemID $=720>$, xem ngày $10 / 05 / 2018$

3. Lê Thi Hằng, Đào Xuân Vinh, Đoàn Huy Hâu, và cs (2002). Một số đặc điểm dịch tế học bệnh bụi phổi silic ở công nhân sản xuất vật liệu ngành xây dựng. Tạp chí $Y$ học thực hành, 408(2), 73 - 75.

4. Arturo Pichel, Gumersindo Rego, Aida Quero, Alejandro Dubois, Cristina Martínez, (2008). High Prevalence and Advanced Silicosis in Active Granite Workers: A Dose-Response Analysis Including FEV1. Journal of Occupational and Environmental Medicine, 50(7), $827-833$.

5. Trình Công Tuấn (2016). Tình hình bênh Bui phổi Silic tại một số cơ sở khai thác, chế biển đá và sản xuất vật liêu xây dựng tỉnh Bình Định năm 2016, Viện nghiển cứu sức khỏe cộng đồng.

6. Huỳnh Thanh Hà và Trịnh Hồng Lân (2008). Khảo sát tình hình bênh nhiểm bui phổi silic nghề nghiệp tại một số cơ sở sản xuất vật liệu xây dựng thuộc cống ty xây dựng Dĩ An - Bình Dương Tạp chí Y học TP. Hồ Chí Minh, 4(12), 240 - 246.

7. Masoud Zare Naghadehi, Farhang Sereshki, Mohammadi F., (2014). Pathological study of the prevalence of silicosis among coal miners in Iran: A case history. Atmospheric Environment, 83, 1 - 5 .

\title{
PHÂN TÍCH DI TRUYỀN TRƯỚC LÀM TỔ $\beta$-THALASSEMIA: MẤT ALEN ĐƯợC KIỂM SOÁT BẰNG PHÂN TÍCH DI TRUYỀN LIÊN KẾT GEN
}

Lê Hoàng ${ }^{1}$, Nguyễn Thị Hoa ${ }^{1}$, Nguyễn Liên Hương ${ }^{2}$, Ngô Văn Nhật Minh ${ }^{3}$, Đặng Tiến Trường ${ }^{3}$

\section{TÓM TẮT}

Mục tiêu: Báo cáo một trường hợp gia đình thực hiện PGT-M bênh $\beta$-Thalassemia có xảy ra hiện tượng $A D O$ được phát hiện bằng phương pháp di truyền liên kết gen. Đối tượng và phương pháp: Gia đình nguy cơ gồm người vợ mang dị hợp tữ đột biến Cd17, người chồng mang di hợp tử đột biến $\mathrm{Cd} 26$ và con gái mang hai đột biến dị hợp tử Cd17 và $\mathrm{Cd} 26$. Phương pháp phân tích di truyền trước làm tổ bệnh đơn gen trước làm tổ thông qua xác định haplotype bị bệnh và không

${ }^{1}$ Bênh viên đa khoa Tâm Anh

2Bềnh viện Phụ sản Trung Ương

${ }^{3}$ Hoc viên quân $Y$

Chịu trách nhiệm chính: Đặng Tiến Trường

Email: truongdtvmmu@gmail.com

Ngày nhận bài: 27.10.2020

Ngày phản biên khoa hoc: 26.11 .2020

Ngày duyệt bài: 9.12.2020 bị bệnh, kĩ thuật giải trình tự Sanger để xác định đột biến. Kết quả: Thiết lập được sơ đồ liên kết gen và các đột biến của gia đỉnh nghiên cứu. Kỹ thuật giải trình tự Sanger không đồng nhất với kết quả phẩn tích di truyền liên kết tại một phôi do nguyên nhân ADO. Kết luận: Hiện tượng ADO gây chẩn đoán sai trong PGT. Do đó, viêc áp dụng đồng thời phương pháp trực tiếp và gián tiếp trong PGT-M bệnh $\beta$-thalassemia là rất cấp thiết để khắc phục $A D O$ và cải thiện độ chính xác của PGT.

Tư khóa: $\beta$-Thalassemia, STR, PGT.

\section{SUMMARY}

PREIMPLANTATION GENETIC TESTING ON

B-THALASSEMIA: CASE REPORT ON ALELLE DROP OUT PHENOMENON OBSERVED BY STR-BASED LINKAGE ANALYSIS

Objective: To report one case performing PGT-M on $\beta$-Thalassemia with ADO phenomenon detected by 
linkage analysis. Materials: At-risk family included wife with $\mathrm{Cd} 17$ heterozygous mutation, husband with $\mathrm{Cd} 26$ heterozygous mutation and son with $\mathrm{Cd} 17 / \mathrm{Cd} 26$ compoud of heterozygous muttaions. Methods: Linkage analysis for haplotyping using STR genotyping. Sanger sequencing for mutation detection. IVF and embryo biopsy for samples. Results: Family tree with linkage analysis and mutation were established. Sanger sequencing results were not concordant with linkage analysis in one embryo due to ADO phenomenon. Conclusions: ADO was the main causes of misdiagnosis. Thus, the combination of direct and indirect diagnosis is needed to overcome this drawback to improve accuracy of PGT.

Key words: $\beta$-Thalassemia, STR, PGT

\section{I. ĐĂT VẤN ĐỀ}

Thalssemia là một trong những bệnh đơn gen phổ biến nhất [3]. Bệnh gồm a-Thalassemia do tổn thương gene a-globin (HBA) và $\beta$ Thalassemia do tổn thương gene $\beta$-globin (HBB), dẫn tới thiếu hụt tương ứng chuỗi a-globin và $\beta$ globin của hồng cầu. Hiện tượng này làm hồng cầu dễ võ gây các triệu chứng của thiếu máu ở nhiều mức độ khác nhau. Trong bệnh Thalassemia, $\beta$-thalassemia phổ biến hơn và phân bố chủ yếu ở Địa Trung Hải, Châu Phi, Trung Đông, Ân Độ và Đông Nam Á [6]. Hiện nay vẫn chưa có phương pháp điều trị triệt để bệnh, do đó việc dự phòng để sinh được người con khỏe manh ở những cặp vợ chồng nguy cơ được ưu tiên hàng đầu. Trong đó, kỹ thuật PGT$M$ là giải pháp dự phòng hiệu quả nhất cho cặp vợ chồng mang gen hoặc đã có con bị bệnh.

Xét nghiệm rối loạn di truyền đơn gen trước chuyển phôi (Preimplantation genetic testing for monogenic disorders, PGT-M) là phương pháp nhằm xác định các phôi không có bất thường $\mathrm{di}$ truyền để chuyển vào tử cung người mẹ, mang thai không bị bệnh. Nhờ vậy, PGT-M giúp tránh phải đình chỉ thai, giảm tỷ lệ mắc bêenh di truyền cho thế hệ sau. Tuy nhiên, PGT-M được tiến hành trên mấu tế bào phôi với lượng $A D N$ rất thấp. Hiện tượng mất alen (Allel DropOut-ADO), ngoại nhiễm là nguyên nhân dẫn tới kết quả không chính xác. Tỷ lệ ADO khá cao, lên tới $30 \%$ [1] [2]. Vì vây, các phương pháp xác định trực tiếp đột biến cần được kết hợp với kĩ thuật phẩn tích di truyền liên kết để kiểm soát $A D O$ và ngoại nhiễm ADN. Môt trong những công cu được sử dụng rộng rãi trong phân tích di truyền liên kết là các trình tự lặp ngắn (Short tandem repeatSTR). Một STR là tập hợp 10-60 lần lặp lại đoạn trình tự ngắn từ 2 đến $6 \mathrm{bp}$, có tính đặc thù ở mỗi cá thể. Một số lượng lớn các STR có tính đa hình cao liêt kết chặt chẽ với một gen đích có thể theo dõi sự di truyền của gen đó qua các thế hệ [2].

Ơ Việt Nam, PGT-M đã được thực hiện được một số năm, tại một số trung tâm di truyền. Tuy nhiên, việc tuẩn thủ các khuyến cáo trong việc kết hợp phương pháp trực tiếp và gián tiếp nhằm kiểm soát kết quả chẩn đoán vẫn chưa được coi trọng đúng mực, đặc biệt kiểm soát ngoại nhiễm $A D N$ và $A D O$. Báo cáo này có sử dung kết hợp phương pháp trực tiếp và gián tiếp để kiểm soát $A D O$. Kết quả PGT-M của ca bệnh này có sự không đồng nhất giữa chẩn đoán trực tiếp và gián tiếp do hiện tượng ADO.

\section{II. ĐỐI TƯợNG VÀ PHƯƠNG PHÁP NGHIÊN CỨU}

2.1. Đối tượng nghiên cứu. Gia đình có người vợ mang kiểu gen dị hợp tử đột biến Cd17, người chồng mang kiểu gen dị hợp tử đột biến Cd26, và người con gái mang đột biến dị hợp tử kép $\mathrm{Cd} 17 / \mathrm{Cd} 26$. Hai vợ chồng tham gia thực hiện IVF thu được 9 phôi ngày 5 . Bộ marker STR phục vụ chẩn đoán PGT-M được thiết lập thành cổng trên gia đình và tiến hành chẩn đoán trên 9 mẫu sinh thiết từ phôi thu được.

\subsection{Phương pháp nghiên cứu}

*Thiết lập bô chi thí STR cho gia đình nghiên cứu. ADN tổng số được tách từ $200 \mu \mathrm{L}$ mấu máu của bố mẹ và con trai bị bệnh bằng bộ QIAamp DNA Mini Kit (QIAGEN). Xác định trực tiếp đột biến của các thành viên thông qua giải trình tự Sanger và kĩ thuật Minisequencing trên gen HBB.

Bộ chỉ thị gồm 15 STR có chỉ số đa hình cao, phân bố ở cả trước gen và sau gen HBB được khảo sát trên mẫu máu của gia đình bằng phương pháp Multiplex $\mathrm{PCR}$ và điện di mao quản. Phản ứng Multiplex PCR tiến hành trong ống $P C R$ tổng thể tích $50 \mu$ l bao gồm $10 \mathrm{ng}$ genomic ADN, 2X QIAGEN Multiplex Master Mix (QIAGEN), 0,01 - 0,4 $\mu \mathrm{M}$ mỗi mồi. Chu trình nhiệt thực hiện trên máy PCR ProFlex 3x32-well (Applied Biosystems), gồm bước hoạt hóa enzyme ban đâu ở $95^{\circ} \mathrm{C}$ trong 15 phút, 30 chu kỳ gồm biến tính ở $94^{\circ} \mathrm{C}$ trong 30 giây, gắn mồi ở $60^{\circ} \mathrm{Ctrong} 90$ giây, kéo dài ở $72^{\circ} \mathrm{C}$ trong 1 phút và gia tăng thêm 6 giây sau mỗi chu kỳ và kéo dài cuối cùng ở $60^{\circ} \mathrm{C}$ trong 30 phút. Sản phẩm Multiplex PCR được phân tích phương pháp bằng điện di mao quản trên hệ thống $3130 X \mathrm{X}$ và phân tích bằng phần mềm Genemapper 5.0. Các haplotype bình thường và đột biến của gia đình nghiên cứu được xác định nhờ phân tích liên kết gen trong gia đình.

*Khảo sát trên mẫu sinh thiết phôi. Phôi ngày 5 được sinh thiết và tiến hành nhân toàn 
bộ hệ gen (WGA), sau đó sản phẩm sau WGA được tiến hành theo các bước Multiplex PCR, điện di mao quản và giải trình tự Sanger để xác định tình trạng bệnh của từng phôi.

\section{KẾT QUẢ NGHIÊN CỨU}

3.1. Xác định đột biến và haplotype đột biến của các mẫu của gia đình. Phân tích liển kết gen nhằm xác định các alen của các STR di truyền cùng với các alen đột biến của gen tổn thương gọi là phân tích haplotype. Tập hợp các alen của các STR liên kết với alen đột biển của gen tổn thương được gọi là haplotype đột biến. Tập hợp các alen của STR liên kết với alen bình thường của gen được gọi là haplotype bình thường. Thông qua điện di mao quản trên hệ thống $3130 X L$ và phân tích bằng phần mềm Genemapper 5.0, xác định được kiểu gen của các STR trên các mẫu của gia đình (Hình 1).

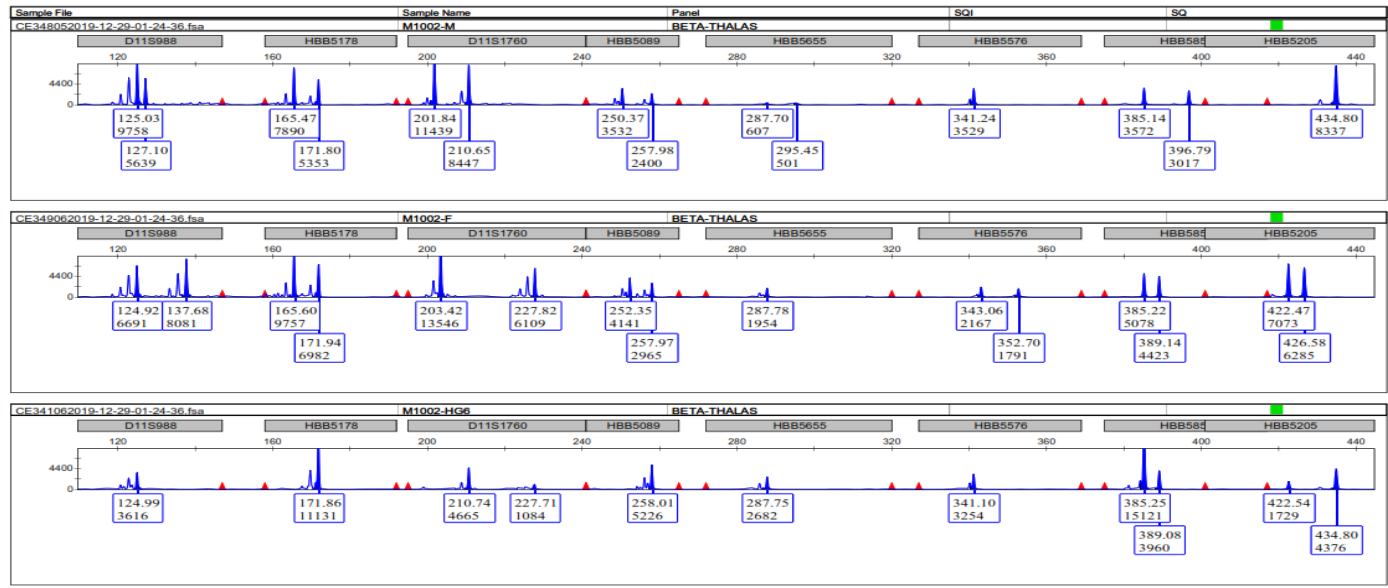

Hình 1. Xác định kiểu gen STR trên phän mềm Genemapper 5.0

Kết quả phân tích gen của các thành viên trong gia đình đã giúp xác định kiểu gen của bố là dị hợp tử cd26; mẹ dị hợp tử cd17 và con mang hai di hợp tử cd26 và cd17. Kết quả này được xác định lại bằng phương pháp giải trình tự trực tiếp và minisequencing. Kết quả phân tích kiểu gen của các STR được thể hiện trên Hình 2. Theo đó, tập hợp các alen của các STR bố, mẹ con lần lượt được sắp xếp thành các cột là các haplotype. Của bố là cột màu trắng và vàng; của mẹ là màu xanh và cam. Con là cột vàng và cam. Người con mang hai tổng thương cd26 và 17 sẽ tương ứng với hai haplotype đột biến cd26 màu vàng, từ bố và haplotype đột biến cd17 màu cam từ mẹ. Nhờ đó, xác định được haplotype màu cam của mẹ là haplotype đột biến $\mathrm{Cd} 17$ và haplotype màu vàng của bố là haplotype đột biến Cd26 (Hình 2).
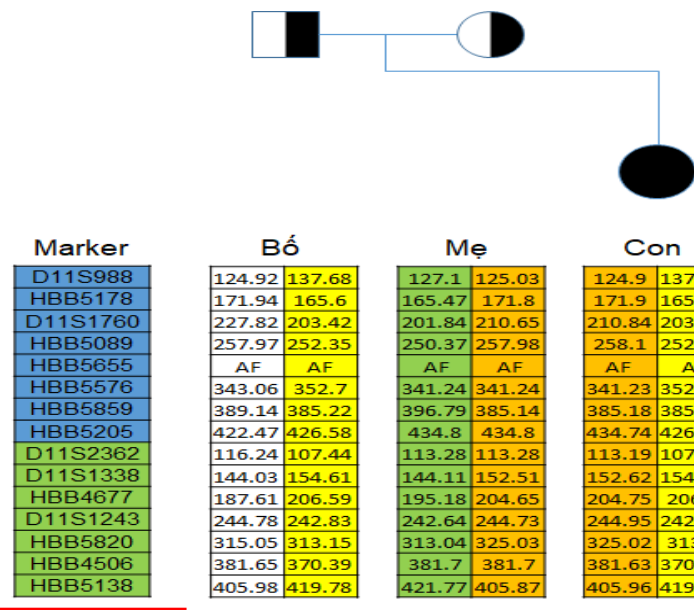

$\beta / \mathrm{Cd} 26$

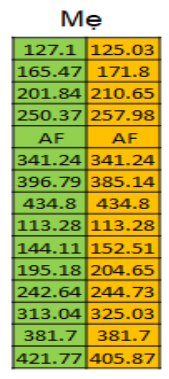

$\beta / \mathrm{Cd17}$
Con

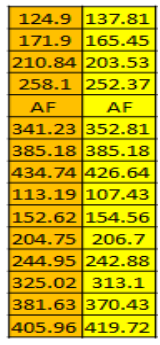

Cd17/Cd26

Hình 2. Sơ đồ phả hệ xác định haplotype trên gia đinh nghiên cúu (AF: Amplification failure)

Như vậy, gia đình nghiên cứu đã được thực hiện thành công quá trình thiết lập và xác định các haplotype đột biến và bình thường.

3.2. Xác định haplotype đột biến trên mẫu sinh thiết phôi. Mẫu phôi được nhận từ trung tâm IVF sẽ được tiến hành khuếch đại toàn bộ hệ gen. Sau đó tiến hành phân tích xác định đột biến cd17 bằng kỹ thuật sanger, đột biến cd26 bằng kỹ thuật minisequencing. Đồng thời việc tiến hành xác định các haplotype đột biến và bình thường bằng kỹ thuật phân tích liên kêt gen.

Kết quả phân tích haplotype của gia đình và các mẫu phôi được trình bày trên Hình 3 .

Kết quả phân tích liên kết gen cho thấy tình trạng của các phôi: mang hai đột biến dị hợp tử Cd17/Cd26 (Phôi 1, 7); dị hợp tử Cd17 (Phôi 3, 4, 6); dị hợp tử Cd26 (Phôi 2,9) và không mang gen (Phôi 5, 8). 


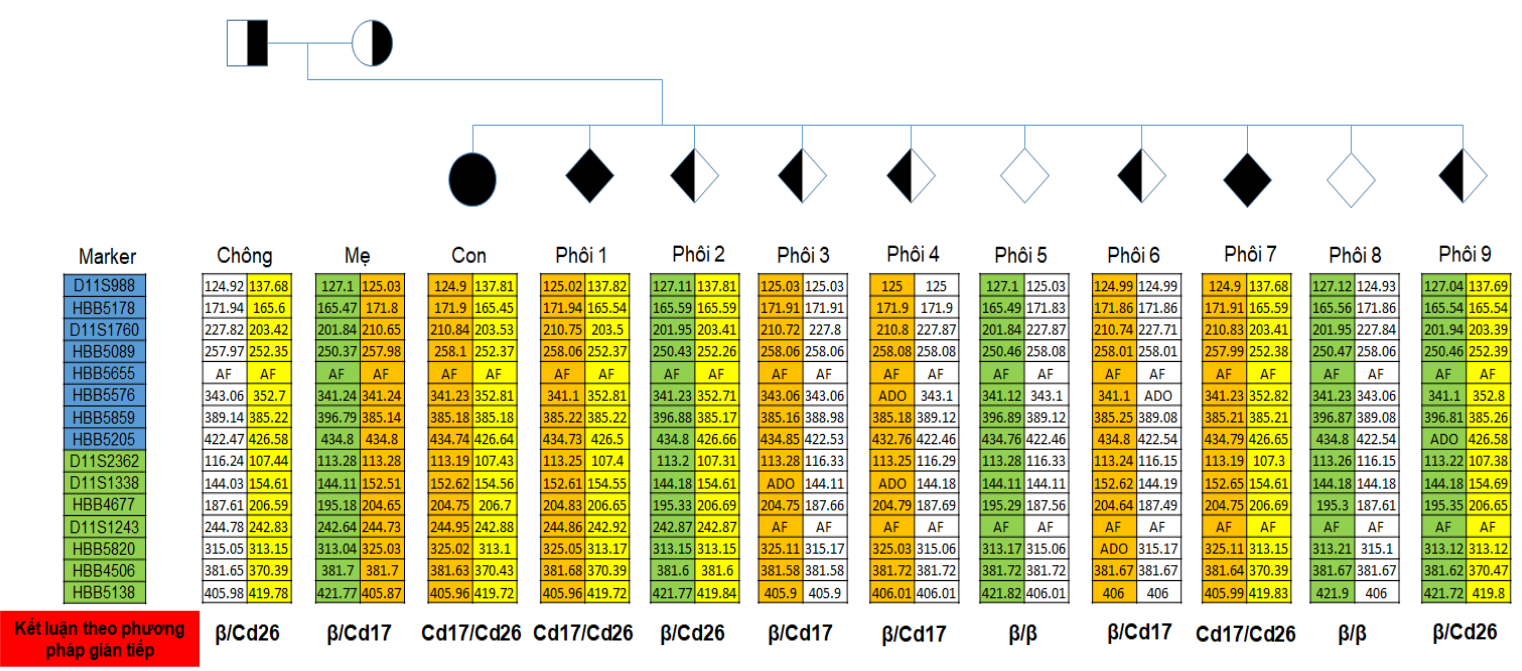

Hình 3. Sơ đồ phả hẹ phân tích di truyền liên kêt trên các mẫu sinh thiết phôi (Độc lập với chẩn đoán trực tiếp bằng phương pháp Sanger)

Kết quả phân tích trực tiếp bằng kỹ thuật giải trình tự cho thấy. Kết quả giải trình tự trực tiếp phù hợp với kết quả phân tích gián tiếp ở hầu hết các phôi trừ phôi số 6 . Sự không thống nhất xuất hiện ở phôi số 6, kết quả giải trình tự Sanger cho thấy peak màu xanh rất cao, peak màu đỏ không đáng kể nên được kết luận là
Cd17 và giải trình tự Sanger ở đột biến Cd26 chỉ xuất hiện một peak màu xanh da trời thể hiện không mang đột biến Cd26. Do đó phương pháp trực tiếp kết luận phôi số 6 không mang gen. Tuy nhiên kết quả phân tích gián tiếp cho thây kiểu gen của phôi số 6 là dị hợp tử Cd17.
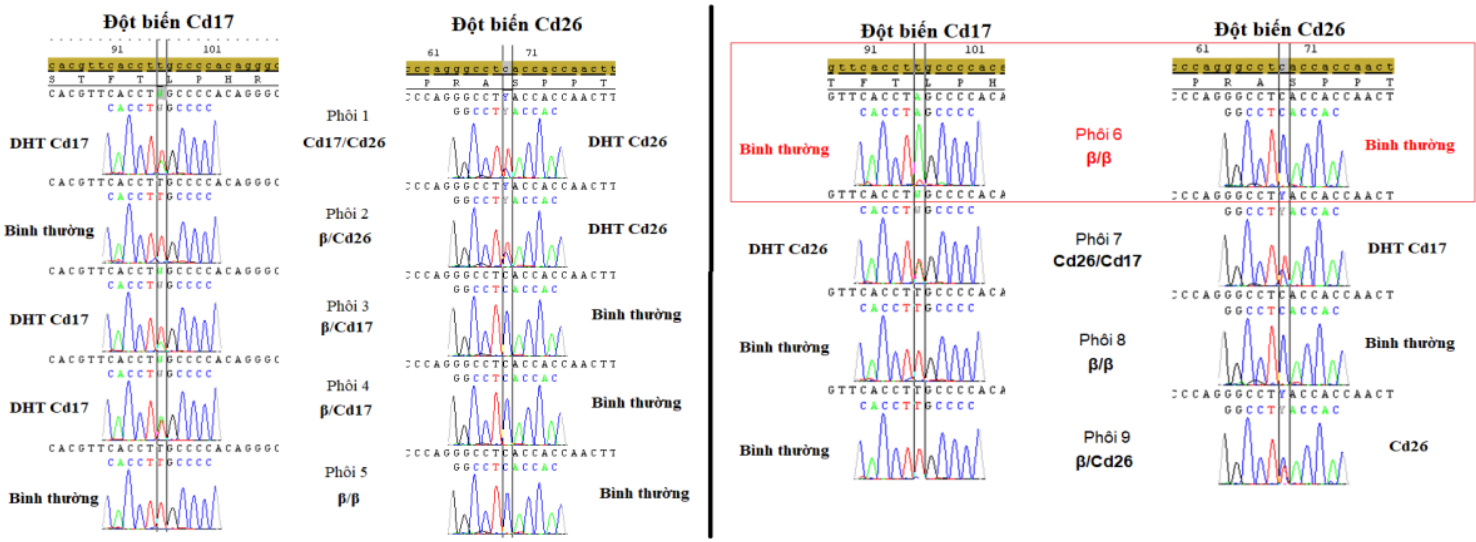

Hình 4. Kết quả giải trinh tự Sanger phát hiện đột biến Cd17 và Cd26 trên các mẫu sinh thiết phôi.

Bộ STR có tính thông tin rất cao đối với gia đình nghiên cứu, đồng thời các STR liên kết chặt chẽ sắp xếp ở cả trước và sau gen mục tiêu. Do đó kết quả phân tích liên kết gen khẳng định hiện tượng $\mathrm{ADO}$ xuất hiện trên mẫu phôi số 6 khiến alen mang đột biến không được khuếch đại thành công, dẫn tới kết quả giải trình tự Sanger không phát hiện được đột biến này. Vì vậy phôi số 6 được kết luận là phôi mang dị hợp tử đột biến Cd17. Trong trường hợp này, phương pháp di truyền liên kết đã giúp kiểm soát được hiện tượng

ADO, tránh dẫn tới chẩn đoán sai lầm.

\section{BÀN LUẬN}

$\beta$-thalassemia là bệnh lí di truyền lặn nhiễm sắc thể (NST) thường, do đột biến gen $\beta$-globin nằm trên cánh ngắn NST 11, gây giảm hoặc mất khả năng tổng hợp chuỗi $\beta$-globin. Bệnh nhân mắc bệnh $\beta$-thalassemia sẽ xuất hiện hội chứng thiếu máu huyết tán, ảnh hưởng tới quá trình phát triển về thể chất và tinh thần. Kỹ thuật xét nghiệm di truyền trước chuyển phôi 
(Preimplantation Genetic Testing -PGT) là sự kết hợp giữa kỹ thuật thụ tinh trong ống nghiệm (In vitro fertilization - IVF) với kỹ thuật chẩn đoán di truyền; qua đó giúp lựa chọn các phôi không mang gen bệnh để chuyển vào tử cung người mẹ, giúp người mẹ mang thai không bị bệnh và sinh con khỏe manh.

Hiện nay, có hai phương pháp chính để chẩn đoán bệnh là chẩn đoán trực tiếp và chẩn đoán gián tiếp. Với khoảng hơn 300 đột biến gen HBB đã được xác định, các phương pháp xác định trực tiểp sẽ gặp khó khăn trong quá trình tối ưu hóa phản ứng để xác định từng đột biến $[4,5]$. Đăc biệt khi thực hiện trên sản phẩm WGA từ mẫu sinh thiết phôi nhằm phục vụ quy trình PGT-M, hiện tượng $A D O$ và ngoại nhiễm có dẫn tới các kết quả sai, tỷ lệ này lên tới $30 \%$ [2]. Áp dụng bộ chỉ thị gồm các STR có tính đa hình cao và liên kết chặt chẽ với gen $\mathrm{HBB}$, qua đó giúp xác định được sự di truyền của tổn thương gen, đồng thời kiểm soát được ngoại nhiễm và hiện tượng $\mathrm{ADO}$ là rất quan trọng trong quy trình PGT-M $\beta$-thalassemia. Theo Hiệp hội hỗ trợ sinh sản và phôi học Châu Âu (ESHRE) 2020 khuyến cáo, việc phối hợp sử dụng kĩ thuật chẩn đoán trực tiếp và gián tiếp là cần thiết trong quy trình PGT-M để tăng độ chính xác của chẩn đoán [2].

Nghiên cứu của chúng tôi báo cáo 1 trường hợp gia đình thực hiện kĩ thuật PGT-M với sự kết hợp của phương pháp trực tiếp và gián tiếp; qua đó phát hiện được hiện tượng ADO khiến chẩn đoán sai nếu chỉ đơn độc dựa vào kết quả trực tiếp, thậm chí có thể dẫn tới việc không chuyển đúng phôi có kiểu gen bình thường cho người mẹ. Kết quả của nghiên cứu đã củng cố vững chắc vai trò quan trọng của phương pháp di truyền liên kết sử dụng các STR liên kết với gen HBB trong PGT-M bệnh $\beta$-thalassemia.

\section{KẾT LUÂ̂N}

Hiện tượng $A D O$ gây chẩn đoán sai trong PGT. Do đó, việc áp dụng đồng thời phương pháp trực tiếp và̀ gián tiếp trong PGT-M bệnh $\beta$ thalassemia là rất cấp thiết để khắc phục $A D O$ và cải thiện độ chính xác của PGT.

\section{TÀI LIÊU THAM KHẢO}

1. G. L. Harton, M. De Rycke và cs. (2011), "ESHRE PGD consortium best practice guidelines for amplification-based PGD", Hum Reprod. 26(1), tr. 33-40.

2. ESHRE PGT-M Working Group, Filipa Carvalho và CS. (2020), "ESHRE PGT Consortium good practice recommendations for the detection of monogenic disorders". 2020(3), tr. hoaa018.

3. Douglas $\mathbf{R}$ Higgs, James Douglas Engel và George Stamatoyannopoulos (2012), "Thalassaemia", The lancet. 379(9813), tr. 373-383.

4. Raffaella Origa (2018), "Beta-thalassemia",

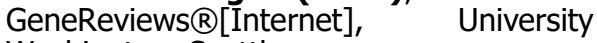
Washington, Seattle.

5. Shahid Raza, Sahrish Farooqi và cs. (2016), "Beta thalassemia: prevalence, risk and challenges". 2(1), tr. 5-7.

6. DJ Weatherall và John $B \% J$ Bulletin of the World Health Organization Clegg (2001), "Inherited haemoglobin disorders: an increasing global health problem". 79, tr. 704-712.

\title{
ĐÁNH GIÁ MỨC Độ THUÂ̂N LỢI CỦA PHẪU THUÂT RĂNG KHÔN BẰNG PHƯƠNG PHÁP AN THẦN ĐÍCH PROPOFOL (TCI)
}

\author{
Mai Đức Hạnh ${ }^{1}$, Nguyễn Quang Bình ${ }^{2}$, Vũ Doãn Tú ${ }^{2}$, \\ Trần Đắc Tiệp ${ }^{1}$, Lê Tịnh ${ }^{\mathbf{1}}$, Nguyễn Trung Kiên ${ }^{1}$
}

\section{TÓM TẮT}

Mục tiêu: Đánh giá mức độ thuận lợi của phẫu thuật răng khôn bằng phương pháp targèt controlled infusion (TCI) propofol. Đối tượng và Phương pháp: thử nghiệm lâm sàng, ngấu nhiên có đối chứng. Tiến hành trên 60 bệnh nhân nhổ răng khôn,

\footnotetext{
${ }^{1}$ Bệnh viện Quân y 103

²Bệnh viện Răng hàm mặt Trung ương Chịu trách nhiệm chính: Mai Đức Hạnh Email: maiduchanh5992@gmail.com Ngày nhận bài: 26.10.2020 Ngày phản biện khoa học: 30.11.2020 Ngày duyệt bài: 10.12.2020
}

tuổi 16 - 50, ASA I, II. Nhóm $1(n=30)$ : Gây mê toàn thân để tiến hành phẫu thuật tại khoa Gây mê, Bệnh viện Răng Hàm Mặt Trung ương Hà Nội. Nhóm 2 ( $\mathrm{n}=$ 30): Sử dụng nồng độ propofol an thần theo đích tại não $(\mathrm{Ce})$ bằng propofol $10 \%$. Phương pháp đánh giá: đă̆c điểm chung, mức độ khó phẫu thự̣̂t răng khôn hàm dưới theo pedersen, thời gian phấu thuật, mức độ cử động của bệnh nhân theo Ellis, mức độ an thẫn $\mathrm{OAA} / \mathrm{S}$, tổng liều lidocain, mức độ hài lòng của phẫu thuật viên theo VAS. Kết quả: Nhóm 2 có tuổi trung bình là $27,17 \pm 9,27$ năm tương đương nhóm 1 là $27,33 \pm 8,62$ năm ( $p>0,05)$; cân nặng trung bình nhóm 2 là $56,67 \pm 10,37 \mathrm{~kg}$ tương đướng nhóm 1 là 55,46 $\pm 10,15 \mathrm{~kg}(\mathrm{p}>0,05)$; tổng liều thuốc tê lidocain là $205.9 \pm 24.95 \mathrm{mg}$ tương đương nhóm 1 là $191.1 \pm$ $31.14 \mathrm{mg}(\mathrm{p}>0,05)$. Nhóm 2 có tổng liều propofol 